\title{
Enantioselective Acute Toxicity Effects and Bioaccumulation of Furalaxyl in the Earthworm (Eisenia foetida)
}

\author{
FANG QIN, YONGXIN GAO, BAOYUAN GUO, PENG XU, JIANZHONG LI AND HUILI WANG* \\ Research Center for Eco-Environmental Sciences, Chinese Academy of Sciences, Beïing, China
}

\begin{abstract}
The enantioselectivities of individual enantiomers of furalaxyl in acute toxicity and bioaccumulation in the earthworm (Eisenia foetida) were studied. The acute toxicity was tested by filter paper contact test. After $48 \mathrm{~h}$ of exposure, the calculated $\mathrm{LC}_{50}$ values of the $R$-form, $r a c$-form, and $S$-form were $2.27,2.08$, and $1.22 \mu \mathrm{g} \mathrm{cm}^{-2}$, respectively. After $72 \mathrm{~h}$ of exposure, the calculated $\mathrm{LC}_{50}$ values were $1.90,1.54$, and $1.00 \mu \mathrm{g} \mathrm{cm}^{-2}$, respectively. Therefore, the acute toxicity of furalaxyl enantiomers was enantioselective. During the bioaccumulation experiment, the enantiomer fraction of furalaxyl in earthworm tissue was observed to deviate from 0.50 and maintained a range of 0.55-0.60; in other words, the bioaccumulation of furalaxyl was enantioselective in earthworm tissue with a preferential accumulation of $S$-furalaxyl. The uptake kinetic of furalaxyl enantiomers fitted the first-order kinetics well and the calculated kinetic parameters were consistent with the low accumulation efficiency. Chirality 26:307-312, 2014. (c) 2014 Wiley Periodicals, Inc.
\end{abstract}

KEY WORDS: furalaxyl; enantioselectivity; earthworm; acute toxicity; bioaccumulation

\section{INTRODUCTION}

Furalaxyl (R, S)-methyl-N-(2, 6-dimethylphenyl)-N-(2furanylcarbonyl)-DL -alaninate, belonging to the acylanilide fungicides, was first introduced in 1977 and is still widely used in the control of plant diseases caused by infection with Albugo candida, Fusarium solani, Peronospora parasitica, Phytophthora sp., and Pythium sp. ${ }^{1,2}$ It can be absorbed by the roots, stalk, and leaves and can move to all parts of the plant with protective, curative, and eradicant action for vegetables and fruits. ${ }^{3}$ Furalaxyl is a chiral fungicide and consists of a pair of enantiomers with $R$ - and $S$-configuration (Fig. 1). Previous studies have shown that the enantiomers of a chiral pesticide have identical physical and chemical properties but they may perform different in the processes of absorption, accumulation, and degradation when confronted with a chiral environment. ${ }^{4,5}$ This makes it necessary to study the biological activity, toxicity, and environmental behavior of the two enantiomers of furalaxyl individually. Sulimma et al. reported that the $R$-furalaxyl decreased more rapidly than the $S$-isomer by Brevibacillus brevis. ${ }^{6}$ Thus, application of commercially available racemic mixtures poses an inevitable biological burden for treated plants and soils. ${ }^{6}$ To further research the effects of chiral pesticides on environmental safety and public health, we checked the uptake and translocation of furalaxyl enantiomers by soil organisms in biological systems. This helps us to address the suitability of replacing pesticide racemic mixtures with single biologically active enantiomers for a more sustainable pesticide use. ${ }^{7-10}$

Earthworms are widely distributed in topsoil and frequently dominant in soil communities. They are appropriate model organisms for bioavailability as they live in close contact with the soil, have a thin and permeable cuticle, and also consume large amounts of soil. Earthworms can thus be considered model organisms for assessing the potential biological effect of the chemicals released into the environment. ${ }^{1-13}$ Several articles have been reported that earthworms were utilized in both toxicity and bioaccumulation studies, ${ }^{14-16}$ but until now there is no report about the enantioselective transfer or bioaccumulation of furalaxyl from soil to earthworm and the toxicity of furalaxyl on earthworm.

(c) 2014 Wiley Periodicals, Inc.
In this study, we selected the commonly used test species, Eisenia foetida, for acute toxicity and bioavailability tests under laboratory conditions. The objectives of this study were to (1) evaluate the acute toxicities of $r a c$-furalaxyl and its enantiomers to earthworm using a filter paper contact test, (2) investigate the enantioselective bioaccumulation of furalaxyl in earthworm from soil.

\section{MATERIALS AND METHODS Chemicals and Reagents}

Racemic furalaxyl and its two enantiomers were synthesized by our laboratory; the purity of $r a c$-enantiomer was $98.0 \%$ and both the enantiomeric purities of $R$-enantiomer and $S$-enantiomer were $97.0 \%$. Acetonitrile (highperformance liquid chromatography [HPLC] grade) was obtained from Fisher Scientific (Fair Lawn, NJ). Silica-based sorbents including $\mathrm{C}_{18}$ $\left(40 \mu \mathrm{m}\right.$ particle size) and primary secondary amine (PSA, Si- $\left(\mathrm{CH}_{2}\right)_{3}-\mathrm{NH}-$ $\left.\left(\mathrm{CH}_{2}\right)_{2}-\mathrm{NH}_{2}\right)(40 \mu \mathrm{m}$ particle size) were obtained from Agela Technologies (Tianjin, China). Water was purified by a Milli-Q (Bedford, MA) system. All other chemicals and solvents were of analytical reagent grade and commercially available.

\section{Synthesis of Racemic and Two Enantiomers of Furalaxyl}

The two furalaxyl enantiomers were prepared via chiral synthesis methods, ${ }^{17-19}$ and the synthetic procedure was the same as synthesis of benalaxyl enantiomers we have discussed in detail. ${ }^{17}$

The preparation of $R$-furalaxyl with methyl $S$-(-)-lactate $(0.77 \mathrm{~mL}$, $8.0 \mathrm{mmol}, 1.0$ equiv) as a starting material followed the experimental procedure we reported ${ }^{17}$ to obtain the light yellow oil N-xylyl-D-methyl alaninate $(1.38 \mathrm{~g})$. Then sodium bicarbonate $(0.26 \mathrm{~g}, 3.1 \mathrm{mmol}, 1.1$ equiv) was added to a solution of N-xylyl-D-methyl alaninate $(0.58 \mathrm{~g}, 2.8 \mathrm{mmol}$, 1.0 equiv) in $15 \mathrm{~mL}$ of toluene, cooled to a temperature ranging from $5-10^{\circ} \mathrm{C}$, and subsequently 2 -furoyl chloride $(0.40 \mathrm{~g}, 3.1 \mathrm{mmol}, 1.1$ equiv)

Contract grant sponsor: National High Technology Research and Development Program (863) of China; Contract grant number: 2012AA06A302.

Contract grant sponsor: National Natural Science Foundation of China; Contract grant numbers: 21277163.41301569.

${ }^{*}$ Correspondence to: Huili Wang, Research Center for Eco-Environmental Sciences, Chinese Academy of Sciences, Shuangqing Road 18, Haidian District, Beijing 100085, China. E-mail: huiliwang@rcees.ac.cn

Received for publication 18 November 2013; Accepted 27 February 2014

DOI: $10.1002 /$ chir.22323

Published online 28 April 2014 in Wiley Online Library

(wileyonlinelibrary.com). 


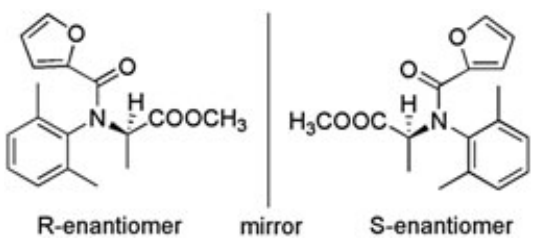

Fig. 1. Structures (absolute configurations) of $R$ - and $S$-furalaxyl.

were slowly added dropwise. After $4 \mathrm{~h}$ at room temperature, the above solution was washed with saturated sodium chloride solution and the organic phase was evaporated in vacuo. The obtained crude product was crystallized with hexane to give $0.57 \mathrm{~g}$ of white crystalline solid $R$-furalaxyl with an enantiomeric $\mathrm{R} / \mathrm{S}$ ratio $=97$ (yield $67 \%$ ).

The preparation of $S$-enantiomer with methyl $R-(+)$-lactate as a starting material followed the same experimental procedure, $\mathrm{S} / \mathrm{R}$ ratio $=97$ (yield $67 \%)$. The preparation of rac-enantiomer with methyl ( \pm )-lactate as a starting material followed the same experimental procedure, $\mathrm{R} / \mathrm{S}$ ratio $=1$ (yield 67\%).

\section{Earthworms}

Mature earthworms (Eisenia foetida), purchased from a northern suburbs farm, Beijing, were maintained in a wooden breeding box $\left(50 \times 50 \times 20 \mathrm{~cm}^{3}\right)$ containing a mixture of soil and cattle manure. Active, sexually mature worms with body masses between 200 and $300 \mathrm{mg}$ were used in the experiment.

\section{Toxicity Test}

According to the OECD guideline 207, a paper contact toxicity assay was used to test the acute toxicity of $r a c$-furalaxyl and its two enantiomers to earthworms. ${ }^{20}$ A range of known concentrations of test substances were prepared with acetone as the solvent. After the depuration period of $24 \mathrm{~h}$ on wet filter paper under dark conditions to evacuate the earthworm gut content, earthworms were rinsed in distilled water and cautiously dried by absorbent paper. One milliliter of solution was pipetted and added to the filter paper $\left(5.5 \times 11.5 \mathrm{~cm}^{2}\right)$ placed in flat-bottomed glass vial. The concentrations of $S$-furalaxyl on filter papers were $0.63,0.95$, $1.26,1.58,1.90,2.21$, and $2.53 \mu \mathrm{g} \mathrm{cm}^{-2}$. The concentrations of $r a c$-furalaxyl and $R$-furalaxyl on filter papers were $1.26,1.58,1.90,2.21,2.53,2.85$, and $3.48 \mu \mathrm{g} \mathrm{cm}^{-2}$. After drying of the solvent under a stream of compressed air, deionized water $(1.0 \mathrm{~mL})$ was added to each vial. Controls were also run in parallel with the carrier solvent alone. Ten replicates for each treatment and each vial containing one worm were done. Each vial was sealed with plastic film with several ventilation holes. After that, all the vials were placed in a room at $20 \pm 2{ }^{\circ} \mathrm{C}$, and mortality of earthworms was assessed after incubation for 48 and $72 \mathrm{~h}$, respectively.

\section{Soil Collection and Earthworm Exposures}

The site to collect soil was a farm of Changping District, Beijing, China. After the superficial vegetation was removed, the top soil $(0-10 \mathrm{~cm})$ was collected. The soils were sieved $(2 \mathrm{~mm})$ and air-dried at room temperature and kept in a dark, dry place. Physicochemical properties of the soil were as follows: sand loam, organic matter, $3.22 \pm 0.12 \%$; clay, $4.23 \pm 0.11$ $\%$; silt, $38.04 \pm 1.14 \%$; sand, $55.12 \pm 1.26 \%$; and $\mathrm{pH}$ (water, ratio $1: 2.5$ ), $7.1 \pm 0.2$.

To ensure that $250 \mathrm{~g}$ of medium was spiked homogeneously with racfuralaxyl, $S$-enantiomer, $R$-enantiomer, the procedure was as follows. First, the chemicals were dissolved respectively in acetone $(10 \mathrm{~mL})$, and then the acetone solution was slowly added to dry soil $(50 \mathrm{~g})$. The spiked soil was left in a fume cupboard overnight to remove acetone. Next, the contaminated dry soil $(50 \mathrm{~g})$ was mixed thoroughly with $200 \mathrm{~g}$ of uncontaminated medium. The final concentrations of $r a c$-furalaxyl in soil were at 20 and $50 \mathrm{mg} \mathrm{kg}^{-1}$ soil. $S$-form and $R$-form were at $10 \mathrm{mg} \mathrm{kg}^{-1}$ soil. Then water $(90 \mathrm{~g})$ was added to each jar to restore the $36 \%$ water content.

Earthworms used in the bioaccumulation test weighed between 200 and $300 \mathrm{mg}$ and were acclimated to the test soils for 1 week prior to the start of the test. We used three replicates per concentration and 10 Chirality DOI 10.1002/chir vehicle control replicates. Earthworms were exposed to each jar containing $340 \mathrm{~g}$ contaminated soil after evacuating their gut contents on moist filter paper for $3 \mathrm{~h}$ at $20^{\circ} \mathrm{C}$. The jars containing contaminated soil and worms were weighed and the loss of water by evaporation was compensated by addition of water every $2 \mathrm{~d}$. All of the vessels were placed in an incubator and maintained at $20 \pm 2^{\circ} \mathrm{C}$ with a photoperiod of $16 \mathrm{~h}$ light and $8 \mathrm{~h}$ dark. Worms were collected after exposure periods $(0.25,0.5,1$, $2,3,5,7,10,14,21$, and $31 \mathrm{~d})$, rinsed with distilled water, and allowed to depurate most of their gut contents. Water on the surface of the worms was dried by absorbent paper cautiously, and then the worms were weighed and frozen at $-20^{\circ} \mathrm{C}$. Soil samples ( $6.8 \mathrm{~g}$ wet weight) from each jar were also stored at $-20^{\circ} \mathrm{C}$.

\section{Sample Extraction and Purification Procedure}

All the samples were thawed for about $15 \mathrm{~min}$ at room temperature. For soil samples (6.8 $\mathrm{g}$ per sample), they were weighed into a $30-\mathrm{mL}$ polypropylene centrifuge tube, followed by addition of $10 \mathrm{~mL}$ acetonitrile containing $1 \%$ of acetic acid. After the mixture was vortexed for $1 \mathrm{~min}$ and exposed to ultrasonic vibration for $20 \mathrm{~min}$, anhydrous $\mathrm{MgSO}_{4}$ $(2.0 \mathrm{~g})$ and $\mathrm{CH}_{3} \mathrm{COONa}(1.0 \mathrm{~g})$ were added. Then the tube was shaken vigorously for $1 \mathrm{~min}$ using a vortex mixer, exposed to ultrasonic vibration for $20 \mathrm{~min}$, and centrifuged at $5000 \mathrm{rpm}$ for $3 \mathrm{~min}$. $1.0 \mathrm{~mL}$ aliquot of the acetonitrile extracts was transferred into a 2-mL centrifuge tube containing PSA $(50 \mathrm{mg}), \mathrm{C}_{18}(50 \mathrm{mg})$, and anhydrous $\mathrm{MgSO}_{4}(100 \mathrm{mg})$ for cleanup. After shaking and centrifugation, the resulting solution was filtered through a $0.22-\mu \mathrm{m}$ filter. Then $0.1 \mathrm{~mL}$ solution was taken and diluted to $10 \mathrm{~mL}$ with acetonitrile for HPLC-dual mass spectrometry (MS/MS) analysis.

For analysis of the earthworms, the samples ( $2.0 \mathrm{~g}$ per sample) were blended with $8 \mathrm{~mL}$ of acetonitrile containing $1 \%$ of acetic acid. The mixture was homogenized with an Ultra-Turrax T18 homogenizer for $30 \mathrm{~s}$, vortex-mixed for $1 \mathrm{~min}$, exposed to ultrasonic vibration for $20 \mathrm{~min}$, and then anhydrous $\mathrm{MgSO}_{4}(1.6 \mathrm{~g})$ and $\mathrm{CH}_{3} \mathrm{COONa}(0.8 \mathrm{~g})$ were added. Then the purification procedure was the same as the above soil sample. Finally, $0.05 \mathrm{~mL}$ solution was taken and diluted to $1 \mathrm{~mL}$ with acetonitrile for HPLC-MS/MS analysis.

\section{Chemical Analysis and Method Validation}

HPLC-MS/MS analyses were performed on a TSQ QUANTUM ACCESS MAX triple quadrupole MS and an Accela 600 pump/autosampler HPLC (Thermo Electron, Hopkinson, MA). The system was controlled and data were collected and analyzed by the Thermo Fisher LC Quan software package (v. 2.7). Enantiomers were separated on a Chiralpak IC column $(4.6 \times 250 \mathrm{~mm}$ i.d., Daicel, Japan) with $5 \mu \mathrm{m}$ particle size. The mobile phase was a mixture of $80 \%$ acetonitrile and $20 \%$ water with a flow rate of $0.35 \mathrm{~mL}$ $\mathrm{min}^{-1}$. Chromatographic separation was conducted at $20^{\circ} \mathrm{C}$ and the injection volume was $10 \mu \mathrm{L}$.

The electrospray ionization (ESI)-MS interface was operated in the positive ion mode with selected reaction monitoring (SRM). The ESI source conditions were as follows: spray voltage, $3200 \mathrm{~V}$; sheath gas pressure, 40 Arb; auxiliary gas pressure, 5 Arb; collision gas (Ar): 1.5 mTorr; vaporizer temperature, $250^{\circ} \mathrm{C}$; capillary temperature, $350^{\circ} \mathrm{C}$. For furalaxyl, $m / z$ $302>242$ was used for quantification, $m / z 302>95$ wase used for confirmation, and collision energies were $30 \mathrm{eV}$ and $16 \mathrm{eV}$, respectively. Racemic furalaxyl was ideally baseline separated and no enantiomerization was observed for furalaxyl under this analytical condition (Fig. 2). The first eluted enantiomer was $S$-form $(12.83 \mathrm{~min})$ and the second one was $R$-form $(14.11 \mathrm{~min})$. Good linear calibration curves were obtained over the concentration range of $1-500 \mathrm{ng} \mathrm{mL}^{-1}$ for $S$-furalaxyl and $R$-furalaxyl. The calibration curves of matrix-matched standard solutions (1-500 ng $\mathrm{mL}^{-1}$ ) by adding blank earthworm and soil sample extracts were also obtained. Comparing the slope of solvent standard curve with matrixmatched standard curve, the slope ratios ranged from $0.86-0.98$, so there was no significant matrix-induced ion signal suppression / enhancement (SSE).

Recovery of furalaxyl enantiomers was determined in blank soil and earthworm samples by being fortified at different concentration levels (0.01, 0.1, 1.0, and $10 \mathrm{mg} \mathrm{kg}^{-1}$ based on five replicates). The samples were left for $1 \mathrm{~h}$ to ensure that the spiked pesticides were evenly distributed 


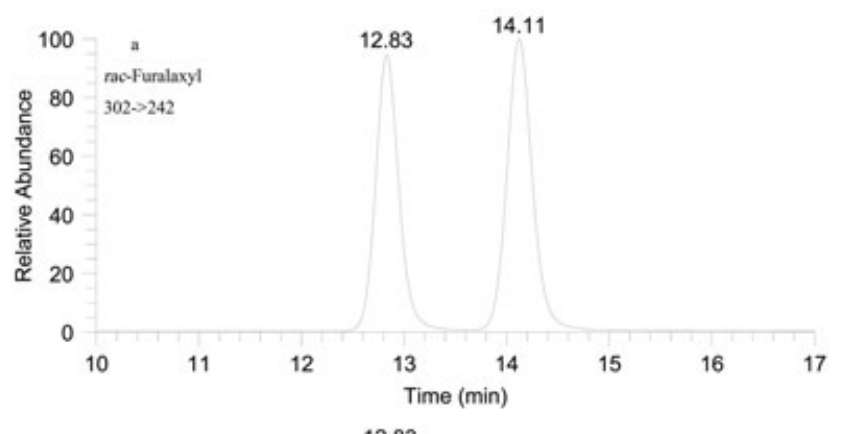

and $k_{2}\left(\mathrm{~d}^{-1}\right)$ denoted the rate constant characterizing the sum of elimination, growth dilution, and metabolic transformation of the two enantiomers in the earthworm, $K$ was the constant ratio of $k_{1}$ and $k_{2}$.

The bioaccumulation factors (BAF) was used to express the relative bioaccumulation capacities of pesticides in the organisms versus the surrounding environmental and was calculated as:

$B A F\left(k g\right.$ dry $\mathrm{kg}^{-1}$ wet weight $)=\frac{C_{\text {worm }}}{C_{\text {soil }}}$

When the uptake and elimination reached steady state during the accumulation phase (i.e., $t=),{ }^{13} \mathrm{Eq}$. (2) may be reduced to:

$C_{\text {worm }}=K C_{\text {soil }}$

$K=\frac{C_{\text {worm }}}{C_{\text {soil }}}$

when steady state was reached, according to Eqs. (3), (4), and (6):

$B A F=K=\frac{k_{1}}{k_{2}}$

The enantiomer fraction (EF) was used as measure the enantioselective behaviors of furalaxyl during the experiment. The EF values range from 0 to 1 , with $\mathrm{EF}=0.5$ representing the racemic mixture. It was defined as:

$E F=\frac{(S)}{((S)+(R))}$

where $(S)$ was the concentration of $S$-furalaxyl and $(R)$ was that of $R$-furalaxyl. A paired $t$-test was carried out to compare the means of the $\mathrm{EF}$ values in earthworm and soil samples with $\mathrm{EF}=0.5$.

\section{RESULTS AND DISCUSSION Acute Toxicity Assay}

The acute toxicity for furalaxyl individual enantiomers and

Fig. 2. Simultaneous stereoselective separation of furalaxyl. (a) rac-furalaxyl (b) S-furalaxyl (c) R-furalaxy.

and then extracted and determined as previously described. The recoveries were calculated by comparing the measured concentrations to the fortified concentrations and the relative standard deviation (RSD) revealed the method precision. The average recoveries for furalaxyl enantiomers ranged between 88 and $97 \%$ in soil, between 80 and $95 \%$ in earthworm tissue with RSD below $16 \%$. There was no significant matrix effect for furalaxyl enantiomers determination with the HPLC-MS/MS method. In this study, the limit of detection (LOD) and limit of quantitation (LOQ) were estimated to be $0.07 \mu \mathrm{g} \mathrm{kg}^{-1}$ and $0.22 \mu \mathrm{g} \mathrm{kg}^{-1}$ for each enantiomer in earthworm tissue and soil sample. Compared with the newly prepared solutions, the stability test of furalaxyl enantiomers was also evaluated in the stock solutions and matrices, which were prepared 2 months previously and stored at $-20^{\circ} \mathrm{C}$. Both enantiomers were stable under the stock solutions and the spiked earthworm and soil samples.

\section{Equilibrium Partitioning Model and Data Analysis}

Equilibrium partitioning theory model was introduced to describe the uptake process of furalaxyl enantiomers. ${ }^{21-23}$ The uptake kinetic parameters and the uptake curve were performed by using the following model equation:

$d C W o r m / d t={ }_{k} C$ Soil $-k_{2} C W o r m$

$C_{\text {Worm }}=\frac{k_{1} C_{\text {Soil }}}{k_{2}}\left[1-\exp \left(-k_{2} t\right)\right]=K C_{\text {Soil }}\left[1-\exp \left(-k_{2} t\right)\right]$

$K=\frac{k_{1}}{k_{2}}$

Where $t$ was the exposure time, $C_{\text {Worm }}\left(\mathrm{mg} \mathrm{kg}^{-1}\right)$ was the concentration of furalaxyl enantiomers in earthworm tissues, $C_{\text {Soil }}\left(\mathrm{mg} \mathrm{kg}^{-1}\right)$ was the concentration in soil, $k_{1}\left(\mathrm{~d}^{-1}\right)$ denoted the uptake rate constant from soil,

racemate was measured by a filter paper contact test and used earthworms (Eisenia foetida) as the test organism. Earthworms take up organic compounds through their skin as well as from feeding on soil particles in gut. Hydrophobic chemicals with a $\log K_{\text {ow }}$ above 5 mainly were absorbed from the gut contents, and chemicals with a $\log K_{o w}$ below 5 mainly were absorbed through the skin in the earthworms. ${ }^{11,24}$ As the $\log K_{\mathrm{ow}}$ for furalaxyl is 2.70 , skin absorption is the main route for furalaxyl in earthworm tissue. So the filter paper contact test is sufficient for assay of the acute toxicity of furalaxyl enantiomers to earthworm.

In the filter paper contact test, the $\mathrm{LC}_{50}$ values calculated are shown in Table 1 . From these results, the $\mathrm{LC}_{50}$ values generally decreased over exposure time, and the calculated $\mathrm{LC}_{50}$ values at both 48 and $72 \mathrm{~h}$ exposure of $R$-furalaxyl, racfuralaxyl, and $S$-furalaxyl were $2.27,2.08$, and $1.22 \mu \mathrm{g} \mathrm{cm}^{-2}$ (48 h); $1.90,1.54$ and $1.00 \mu \mathrm{g} \mathrm{cm}^{-2}(72 \mathrm{~h})$, respectively. These results indicated that the acute toxicity of furalaxyl enantiomers was enantioselective to earthworm, and $R$-furalaxyl was the least toxic compared with racemate and $S$-form. The order of toxicity potency at both 48 and $72 \mathrm{~h}$ was $S$-form racemate $>R$-form. However, for benalaxyl and metalaxyl, which have a similar structure with furalaxyl, the fungicidally active $R$-benalaxyl was more toxic to earthworm than $S$-benalaxyl, and rac-metalaxyl exhibited more than two times the toxicity than $R$-metalaxyl. ${ }^{14,24}$ After $48 \mathrm{~h}$ of exposure, the calculated $\mathrm{LC}_{50}$ values of $R$-benalaxyl, rac-benalaxy and $S$-benalaxyl were $4.99,5.08$, and $6.66 \mu \mathrm{g} \mathrm{cm}^{-2}$, and the $\mathrm{LC}_{50}$ values of $R$-metalaxyl and rac-metalaxyl were 52 and $22 \mu \mathrm{g} \mathrm{cm}^{-2}$, respectively. ${ }^{14,24}$ Thus, the order of acute toxicity potency of 
TABLE 1. Calculated $\mathrm{LC}_{50}$ values for enanatiomers of furalaxyl

\begin{tabular}{lcccccccc}
\hline & \multicolumn{3}{c}{ Exposure time $(48 \mathrm{~h})$} & & \multicolumn{3}{c}{ Exposure time $(72 \mathrm{~h})$} \\
\cline { 2 - 3 } Chemicals & $\mathrm{LC}_{50}\left(\mu \mathrm{g} \mathrm{cm}^{-2}\right)$ & $95 \%$ Confidence intervals & $R^{2}$ & & $\mathrm{LC}_{50}\left(\mu \mathrm{g} \mathrm{cm}^{-2}\right)$ & & $95 \%$ Cofidence intervals & $R^{2}$ \\
\hline$R$-furalaxyl & 2.27 & $1.87-2.74$ & 0.965 & & 1.90 & $1.54-2.19$ & 0.933 \\
rac-furalaxyl & 2.08 & $1.72-2.40$ & 0.959 & & 1.54 & & $1.06-1.82$ & 0.960 \\
$S$-furalaxyl & 1.22 & $0.55-1.76$ & 0.952 & & 1.00 & & $0.69-1.23$ & 0.954 \\
\hline
\end{tabular}

$R^{2}$ represents the correlation coefficient.

acylanilide fungicides to worms was $S$-furalaxyl $>$ rac-furalaxyl $R$-furalaxyl $>R$-benalaxyl $>r a c$-benalaxyl $>S$-benalaxyl $>r a c$ metalaxyl $>R$-metalaxyl. The change of acyl side chains in acylanilide fungicides may result in the chemicals' toxicology difference, and furanylcarbonyl toxicity potency may be higher than phenylacetyl and methoxyacetyl.

\section{Bioaccumulation and Elimination in Earthworm}

The concentrations of the two furalaxyl enantiomers in earthworm tissue and soil were determined. The concentrations in soil samples appeared to decrease 20-30\% after 31 days exposure at different concentrations (Fig. 3). The chemicals' degradation and biotransformation may be the main reasons for the loss of soil concentrations. Residue of the main metabolite, furalaxyl acid, was lower in soil. The concentrations of furalaxyl enantiomers were almost the same in spiked soil (20 and $50 \mathrm{mg} \mathrm{kg}^{-1}$ ) and the EF values were 0.5 at the beginning and remained so with almost no change during the course of the experiment $(P>0.050)$.

The concentrations of furalaxyl individual enantiomers were observed in earthworm tissue at the same sample point during the bioaccumulation period. The concentrations of $S$-form were higher than that of $R$-form in spiked soils (Fig. 3).
The $\mathrm{EF}$ values in earthworm tissue were observed to deviate from 0.50 and maintained a range of $0.55-0.60$, as shown in Figure 4 , and these deviations were significant $(P<0.001)$. The results implied that the bioaccumulation of furalaxyl in earthworm tissue was enantioselective, with preferential accumulation of $S$-enantiomer. The possible metabolite of furalaxyl acid was not found in any dose of earthworm tissue. According to Figure 3a,b, a higher rate of application of furalaxyl resulted in a higher concentration in earthworm tissue, and the concentration of both enantiomers reached the highest levels on the 2-3rd day. After a short-time decrease, the concentrations increased gradually and obtained the maximum values again on the 10th day. Thereafter, the concentrations in earthworm tissue declined and reached steady state as the duration of exposure increased. The peak-shaped accumulation curves were observed in the bioaccumulation of furalaxyl by earthworm (Fig. 3). According to Xu et al., ${ }^{24}$ peak-shaped accumulation curves happened while organic compound bioavailability decreased. Although the exact causes are not known yet, sorption and desorption from soil organic matter, or pesticides biodegradation and excretion may all play important roles in the peak-shaped accumulation patterns in our study. ${ }^{25-27}$

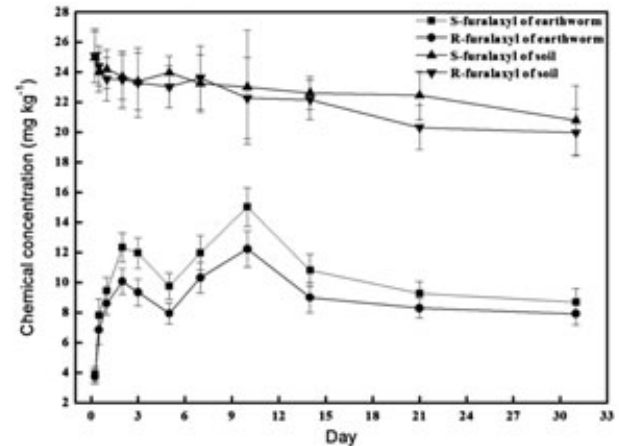

a) rac-furalaxyl $50 \mathrm{mg} / \mathrm{kg}$

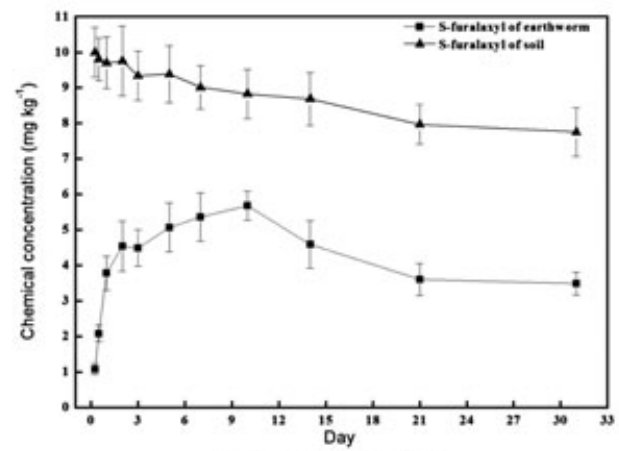

c) $S$-furalaxyl $10 \mathrm{mg} / \mathrm{kg}$

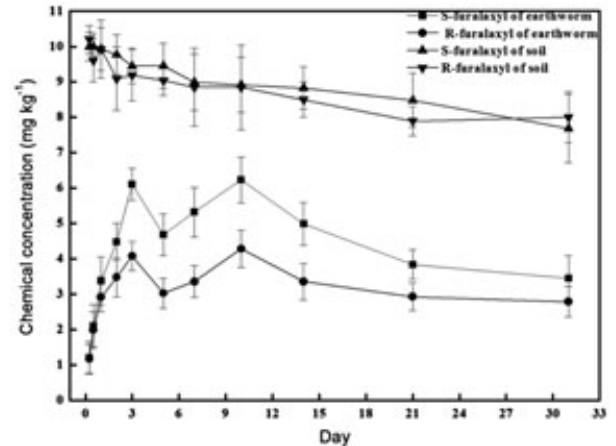

b) rac-furalaxyl $20 \mathrm{mg} / \mathrm{kg}$

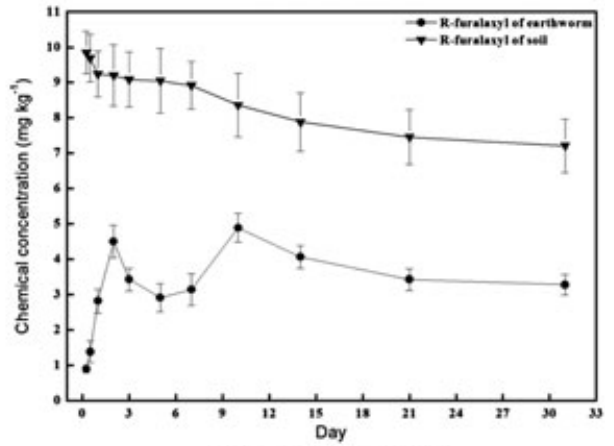

d) $R$ - furalaxy $10 \mathrm{mg} / \mathrm{kg}$

Fig. 3. Average concentrations of $S$-furalaxyl and $R$-furalaxyl in soil and earthworm. 


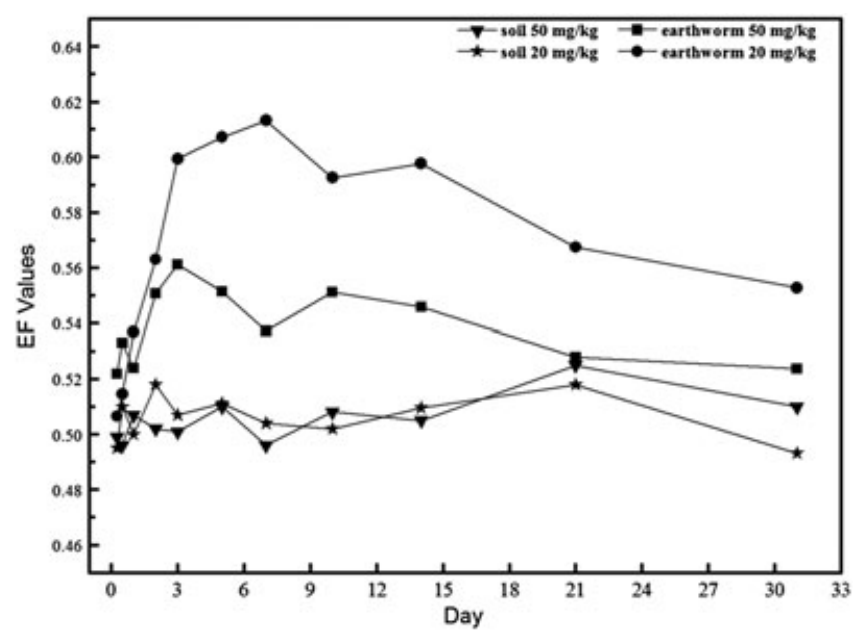

Fig. 4. Enantiomeric fraction (EF) of furalaxyl residues in soil and earthworm.

In the bioaccumulation phase, the concentrations in earthworm tissue showed peak-shaped curves around 2 to $10 \mathrm{~d}$ for furalaxyl enantiomers (Fig. 3). At the initial stage, the concentrations of furalaxyl enantiomers in soil were high, and the earthworms responded to these in availability with a high uptake rate. After the uptake of organic pollutants by earthworm increased rapidly in the body at first, it increased slowly or even decreased (Fig. 3), then increased rapidly to reach the highest level. This process was governed by an increase of sorption and slow desorption furalaxyl from soil organic matter, biotransformation, or a decreasing concentration in the soil, or elimination or metabolic transformation of compounds from earthworm induced by enzymes. At the last bioaccumulation stage, the concentrations of furalaxyl enantiomers in earthworm reached steady state, and the uptakeelimination rate approached a steady state smoothly at a body residue consistent with the expected basis of equilibrium. This conclusion was consistent with previous studies. ${ }^{24,27}$ The appearance of peak-shaped accumulation curves in our experiment was affected by the change of bioavailability in earthworms and the chemicals' transportation and fate in the soil.

The calculated BAFs according to Eq. (4) of two enantiomers are shown in Figure 5. The values of BAFs at the low

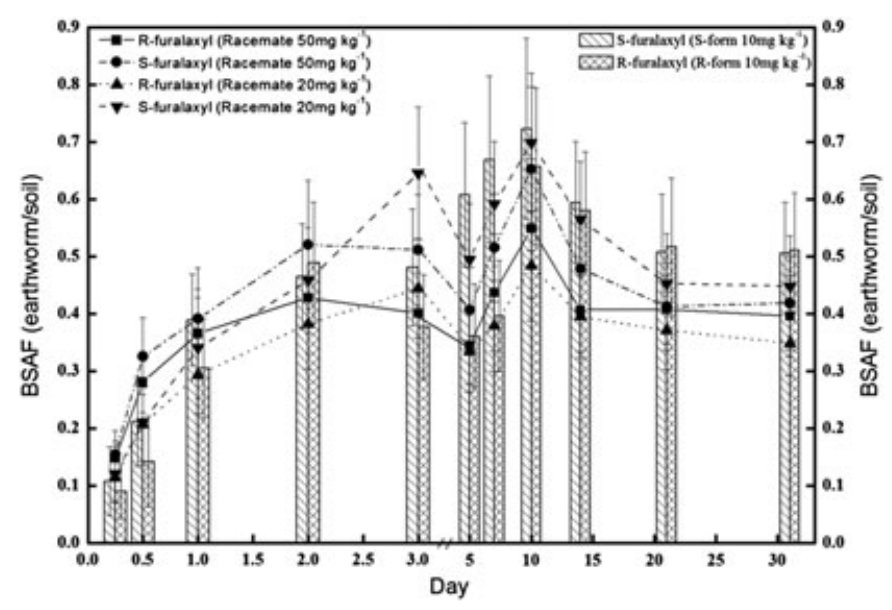

Fig. 5. Calculated bioaccumulation factors (BAF) for the two enantiomers of furalaxyl by sampling day at different spiked concentration. concentration group were no different from that at a high concentration level. The BAF values of $S$-form were larger than that of $R$-form $(P<0.001)$, indicating that the $S$-form was preferentially accumulated over the $R$-form in earthworm tissue. It can be concluded that the accumulated concentration of furalaxyl in earthworm tissue via single skin exposure and gut absorption was enantioselective. The BAF values of furalaxyl were smaller than benalaxyl and larger than metalaxyl. The results should relate to the chemicals hydrophobicity and lipophilicity, since it was already confirmed that the chemicals hydrophobicity and lipophilicity can affect the chemicals transformation and bioaccumulation in earthworm tissue. ${ }^{12,28}$ Although both enantiomers showed low accumulation efficiency in earthworms, furalaxyl was dissipated with $\mathrm{DT}_{50} 31-65 \mathrm{~d}$ in soil ${ }^{29}$ and was relatively persistent in the environment and earthworms. Therefore, the result of furalaxyl bioaccumulation in earthworms could help provide data for evaluating the environmental risk. Earthworms are widely distributed in topsoil and consumed by predator organisms and so furalaxyl enantiomers may have trophic transfer and/or bioaccumulation and/or harmful effects on organisms through food chains.

In this work, we also investigated whether furalaxyl enantiomers in earthworm tissue were caused by enantiomerization or not by exposing earthworm to the soil contaminated with enantiopure $R$-furalaxyl and $S$-furalaxyl, respectively. The results (Fig. 3c,d) showed that furalaxyl was configurationally stable in earthworm tissue and soil during a period of $31 \mathrm{~d}$, showing no interconversion of $R$ - to $S$-enantiomers, and vice versa. We have reported that ${ }^{17}$ benalaxyl was enantiomerization and enantioselective bioaccumulated in Tenebrio molitor larvae from wheat bran and the rate of enantiomerization of $R$-benalaxyl was higher than that of $S$-benalaxyl. So furalaxyl enantiomers may have enantiomerization in other organisms or higher animals, and it is important to utilize enantiopure enantiomers of chiral pesticides for more precise risk assessment in biological systems.

\section{Kinetic Analysis}

We tested if the temporal course of furalaxyl uptake into earthworms from the spiked soil can be described by the equilibrium partitioning model. By fitting the average concentrations in earthworm and time into Eq. (2), a nonlinear regression fitting technique provided by SPSS 16.0 (Chicago, IL), and the regression results are shown in Table 2.

The trends of $S$-furalaxyl and $R$-furalaxyl fitted the first-order kinetics under different exposure concentration groups $(r=0.797-0.877,0.819-0.858$, respectively). The results indicated that furalaxyl enantiomers in earthworm tissue were proportional to the concentration in soil, and the accumulation from soil was an equilibrium partition process. ${ }^{30}$ The rate constants were calculated applying the estimated values obtained from the regression results. The approximations of the rate constants for $S$-furalaxyl were 0.605-0.934 $\left(k_{1}\right)$, 1.227-2.079 $\left(k_{2}\right)$, and 0.449-0.493 $(K)$, and the rate constants for $R$-furalaxyl were $0.500-0.893\left(k_{1}\right), 1.347-2.372\left(k_{2}\right)$, and $0.342-0.377(K)$. The uptake rate $\left(k_{1}\right)$ of furalaxyl was much lower than the rate of elimination and metabolism $\left(k_{2}\right)$ in earthworm tissue and this estimate was in accord with the low accumulation efficiency (BAF) we have discussed. The $K$ values (Table 2) of furalaxyl enantiomers according to Eq. (2) were consistent with the BAF for earthworms (Fig. 5) when earthworm bioaccumulation reached steady state. A 
TABLE 2. Calculated kinetic parameter of furalaxyl enantiomers

\begin{tabular}{lccccc}
\hline Exposure group & Enantiomers & $K$ & $k_{1}$ & $k_{2}$ & $r$ \\
\hline $50 \mathrm{mg} \mathrm{kg}^{-1}$ rac-furalaxyl & $S$-furalaxyl & $0.449 \pm 0.026$ & $0.934 \pm 0.286$ & $2.079 \pm 0.676$ & 0.797 \\
$20 \mathrm{mg} \mathrm{kg}^{-1}$ rac-furalaxyl & $R$-furalaxyl & $0.377 \pm 0.019$ & $0.893 \pm 0.238$ & $2.372 \pm 0.668$ & 0.819 \\
& $S$-furalaxyl & $0.493 \pm 0.034$ & $0.605 \pm 0.192$ & $1.227 \pm 0.419$ & 0.846 \\
$10 \mathrm{mg} \mathrm{kg}^{-1} S$-furalaxyl & $R$-furalaxyl & $0.342 \pm 0.017$ & $0.623 \pm 0.159$ & $1.820 \pm 0.494$ & 0.858 \\
$10 \mathrm{mg} \mathrm{kg}^{-1} R$-furalaxyl & $S$-furalaxyl & $0.466 \pm 0.026$ & $0.635 \pm 0.171$ & $1.363 \pm 0.394$ & 0.877 \\
& $R$-furalaxyl & $0.371 \pm 0.025$ & $0.500 \pm 0.162$ & $1.347 \pm 0.470$ & 0.844 \\
\hline
\end{tabular}

paired $t$-test showed that there was a significant difference in the $K$ values between the two furalaxyl enantiomers $(P=0.045)$. The results also indicated that the accumulation, degradation, and elimination of furalaxyl in earthworm tissue were enantioselective.

\section{CONCLUSION}

In this study, the acute toxicity and bioaccumulation of furalaxyl enantiomers to earthworm were assayed. The results of acute toxicity showed that $S$-furalaxyl was the more toxic compared with the racemate and $R$-furalaxyl to the nontarget organism, earthworm. The concentrations of two furalaxyl enantiomers in soil and earthworm were also determined and there was a significant trend of enantioselective bioaccumulation in the earthworm with a preferential accumulation of $S$-furalaxyl at four levels of exposure. Thus, we advise that $R$-furalaxyl with fungicidal activity higher than the $S$-enantiomer replace $r a c$-furalaxyl for a more sustainable pesticide use for environmental safety and public health.

\section{LITERATURE CITED}

1. Davidse LC, Gerritsma OCM, Ideler J, Pie K, Velthuis GCM. Antifungal modes of action of metalaxyl, cyprofuram, benalaxyl and oxadixyl in phenylamide-sensitive and phenylamide-resistant strains of Phytophthora megasperma f. sp. medicaginis and Phytophthora infestans. Crop Prot 1988;7:347-355.

2. Zadra C, Marucchini C, Zazzerini A. Behavior of metalaxyl and its pure R-enantiomer in sunflower plants (Helianthus annus). J Agric Food Chem 2002;50:5373-5377.

3. Zhang H, Wang X, Jin L, Qian M, Wang X, Xu H, Qi P, Wang Q, Wang M. Enantioselective determination of acylamino acid fungicides in vegetables and fruits by chiral liquid chromatography coupled with tandem mass spectrometry. J Sep Sci 2012;35(15):1869-1876

4. Williams A. Opportunities for chiral agrochemicals. Pestic Sci 1996;46:3-9.

5. Hegeman WJM, Laane RWPM. Enantiomeric enrichment of chiral pesticides in the environment. Rev Environ Contam Toxicol 2002;173:85-116.

6. Sulimma L, Bullach A, Kusari S, Lamshöft M, Zühlke S, Spiteller M. Enantioselective degradation of the chiral fungicides metalaxyl and furalaxyl by Brevibacillus brevis. Chirality 2013;25:336-340.

7. Garrison AW. Probing the enantioselectivity of chiral pesticides. Environ Sci Technol 2006;40:16-23.

8. Magrans JO, Alonso-Prados JL, García-Baudín JM. Importance of considering pesticides stereoisomerism-proposal of a scheme to apply Directive 91/414/CEE framework to pesticide active substances manufactured as isomeric mixtures. Chemosphere 2002;49:461-469.

9. Ye J, Zhao M, Liu J, Liu W. Enantioselectivity in environmental risk assessment of modern chiral pesticides. Environ Pollut 2010;158:2371-2383.

10. Celis R, Gámiz B, Adelino MA, Hermosín MC, Cornejo J. Environmental behavior of the enantiomers of the chiral fungicide metalaxyl in Mediterranean agricultural soils. Sci Total Environ 2013;444:288-297.
11. Jager T, Fleuren RHLJ, Hogendoorn EA, De Korte G. Elucidating the routes of exposure for organic chemicals in the earthworm, Eisenia andrei (Oligochaeta). Environ Sci Technol 2003;37:3399-3404.

12. Jager T, Van Der Wal L, Fleuren RHLJ, Barendregt A, Hermens JLM. Bioaccumulation of organic chemicals in contaminated soils: evaluation of bioassays with earthworms. Environ Sci Technol 2005;39:293-298.

13. Wang H, Chen J, Guo B, Li J. Enantioselective bioaccumulation and metabolization of diniconazole in earthworms (Eisenia fetida) in an artificial soil. Ecotoxicol Environ Saf 2014;99:98-104.

14. Xu P, Diao J, Liu D, Zhou Z. Enantioselective bioaccumulation and toxic effects of metalaxyl in earthworm Eisenia foetida. Chemosphere 2011;83:1074-1079.

15. Yu D, Li J, Zhang Y, Wang H, Guo B, Zheng L. Enantioselective bioaccumulation of tebuconazole in earthworm Eisenia fetida. J Environ Sci 2012;24:2198-2204.

16. Diao J, Xu P, Liu D, Lu Y, Zhou Z. Enantiomer-specific toxicity and bioaccumulation of alpha-cypermethrin to earthworm Eisenia fetida. J Hazard Mater 2011;192:1072-1078

17. Gao Y, Chen J, Wang H, Liu C, Lv X, Li J, Guo B. Enantiomerization and enantioselective bioaccumulation of benalaxyl in Tenebrio molitor larvae from wheat bran. J Agric Food Chem 2013;61:9045-9051.

18. Effenberger F, Burkard U, Willfahrt J. Enantioselektive synthese $\mathrm{N}$-substituierter $\alpha$-Aminocarbonsäuren aus $\alpha$-Hydroxycarbonsäuren. Liebigs Ann Chem 1986;2:314-333

19. Palla O, Mirenna L, Colombo L, Zini G, Filippini L, Zanardi G. Fungicidal compositions based on (N-phenylacetyl-N-2, 6-xylyl) methyl alaninate. U. S. 6228885 B1; 2001 (English).

20. Organization for Economic Cooperation and Development. Guidelines for testing of chemicals, earthworm, acute toxicity tests. Washington, DC: OECD; 1984.

21. Connell DW, Markwell RD. Bioaccumulation in the soil to earthworm system. Chemosphere 1990;20:91-100.

22. Krauss M, Wilcke W, Zech W. Availability of polycyclic aromatic hydrocarbons (PAHs) and polychlorinated biphenyls (PCBs) to earthworms in urban soils. Environ Sci Technol 2000;34:4335-4340.

23. Armitage JM, Gobas FA. A terrestrial food-chain bioaccumulation model for POPs. Environ Sci Technol 2007;41:4019-4025.

24. Xu P, Liu D, Diao J, Lu D, Zhou Z. Enantioselective acute toxicity and bioaccumulation of benalaxyl in earthworm (Eisenia fedtia). J Agric Food Chem 2009;57:8545-8549

25. Reinecke AJ, Nash RG. Toxicity of 2,3,7,8-TCDD and short term bioaccumulation by earthworms (Oligochaeta). Soil Biol Biochem 1984;16:45-49.

26. Ma WC, Immerzeel J, Bodt J. Earthworm and food interactions on bioaccumulation and disappearance in soil of polycyclic aromatic hydrocarbons: studies on phenanthrene and fluoranthene. Ecotoxicol Environ Saf 1995;32:226-232.

27. Jager T, Antón Sánchez FA, Muijs B, Van der Velde EG, Posthuma L. Toxicokinetics of polycyclic aromatic hydrocarbons in Eisenia andrei (Oligochaeta) using spiked soil. Environ Toxicol Chem 2000;19:953-961.

28. Jager T. Mechanistic approach for estimating bioconcentration of organic chemicals in earthworms (Oligochaeta). Environ Toxicol Chem 1998;17:2080-2090.

29. The e-Pesticide Manual, version 3.0. British Crop Protection Council; 2003.

30. Liang X, Zhu S, Chen P, Zhu L. Bioaccumulation and bioavailability of polybrominated diphenyl ethers (PBDEs) in soil. Environ Pollut 2010;158:2387-2392. 